\title{
Hierarchically Porous Silk/Activated-Carbon Composite Fibres for Adsorption and Repellence of Volatile Organic Compounds
}

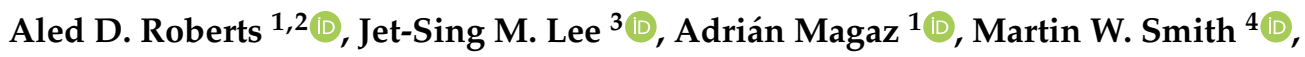 \\ Michael Dennis ${ }^{4}$, Nigel S. Scrutton ${ }^{2}$ and Jonny J. Blaker ${ }^{1,2, *(D)}$ \\ 1 Bio-Active Materials Group, Department of Materials \& Henry Royce Institute, The University of \\ Manchester, Manchester M13 9PL, UK; aled.roberts@manchester.ac.uk (A.D.R.); \\ adrian.magaz@postgrad.manchester.ac.uk (A.M.) \\ 2 Future Biomanufacturing Research Hub (FBRH), Manchester Institute of Biotechnology, The University of \\ Manchester, Manchester M1 7DN, UK; nigel.scrutton@manchester.ac.uk \\ 3 Institute for Integrated Cell-Material Sciences, Institute for Advanced Study, Kyoto University, Yoshida, \\ Sakyo-ku, Kyoto 606-8501, Japan; lee@macro.t.u-tokyo.ac.jp \\ 4 Defence Science and Technology Laboratory (Dstl), Porton Down, Salisbury SP4 0JQ, UK; \\ MWSMITH@dstl.gov.uk (M.W.S.); MRDENNIS@mail.dstl.gov.uk (M.D.) \\ * Correspondence: jonny.blaker@manchester.ac.uk; Tel.: +44-0161-306-3587
}

Academic Editor: Yasumoto Nakazawa

Received: 4 February 2020; Accepted: 5 March 2020; Published: 7 March 2020

\begin{abstract}
Fabrics comprised of porous fibres could provide effective passive protection against chemical and biological (CB) threats whilst maintaining high air permeability (breathability). Here, we fabricate hierarchically porous fibres consisting of regenerated silk fibroin (RSF) and activated-carbon (AC) prepared through two fibre spinning techniques in combination with ice-templating-namely cryogenic solution blow spinning (Cryo-SBS) and cryogenic wet-spinning (Cryo-WS). The Cryo-WS RSF fibres had exceptionally small macropores (as low as $0.1 \mu \mathrm{m}$ ) and high specific surface areas (SSAs) of up to $79 \mathrm{~m}^{2} \cdot \mathrm{g}^{-1}$. The incorporation of AC could further increase the SSA to $210 \mathrm{~m}^{2} \cdot \mathrm{g}^{-1}$ (25 wt.\% loading) whilst also increasing adsorption capacity for volatile organic compounds (VOCs).
\end{abstract}

Keywords: porous fibres; activated carbon; ice-templating; ice segregation induced self-assembly; silk fibroin; wet spinning; solution blow spinning; freeze casting

\section{Introduction}

The current generation of air-permeable chemical and biological (CB) resistant clothing, such as Joint Service Lightweight Integrated Suit Technology (JSLIST), consists of a particulate activated carbon (AC) adsorbent layer laminated between multiple layers of fabric-including a hydrophobic outer layer and soft inner layer [1,2]. Combining the properties of these layers into a single material could reduce the physiological burden on the user through mass reduction and enhanced diffusive and evaporative heat transport. Fabrics comprised of porous fibres with a significant capacity to adsorb and repel volatile organic compounds (VOCs) could help achieve this goal. In particular, a hierarchical structure of pores-where networks of larger macropores $(>50 \mathrm{~nm}$ ) provide effective diffusion and access to smaller meso- $(2-50 \mathrm{~nm})$ and micropores $(<2 \mathrm{~nm})$ - could provide effective rapid adsorption activity whilst maintaining high permeability and relatively low mass [3]. Furthermore, fibres with micron-scale surface features could also enhance liquid repellence through a 'lotus-leaf' type effect-repelling liquid VOC droplets as well as dirt, dust and mud [4].

Although other highly porous materials such as metal organic frameworks (MOFs) and silicates have demonstrated exceptional adsorption and degradation activity against various chemical warfare 
agents (CWAs), [1,5-7] their relatively poor chemical and physical stability and high cost of manufacture mean they are unlikely to replace low-cost ACs (which can also effectively catalyse the degradation of CWAs [8]) for general applications. The brittle nature and poor mechanical properties of microporous materials such as ACs, MOFs and silicates make them unsuitable for use as stand-alone materials in fabrics; instead, they need to be combined with another material with suitable physical properties in order to be incorporated into a garment. This can be achieved by decorating the surface of fibres with a porous material, $[1,5,6]$ but loss of physical attachment means durability can be a significant issue.

In this work, we reprocess silkworm silk into aqueous regenerated silk fibroin (RSF) solutions before spinning into porous fibres via two cryogenic spinning techniques, namely Cryogenic Solution Blow Spinning (Cryo-SBS) and Cryogenic Wet Spinning (Cryo-WS). Cryogenically freezing hydrated fibres results in ice-segregation-induced self-assembly (ISISA) which, after freeze-drying, produces a macroporous ice-templated structure (Figure 1) [9-18]. By spinning colloidal suspensions of AC in RSF, macroporous fibres loaded with AC can be obtained-increasing the specific surface area (SSA), hydrophobicity and adsorption capacity for VOCs. A summary of the conditions employed to prepare samples, along with the most relevant physical properties, is given in Table 1.

(a)

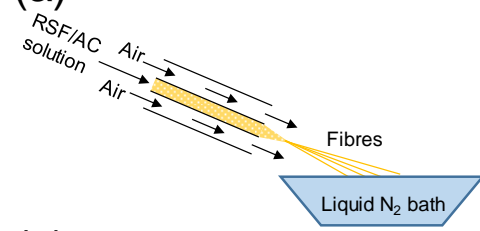

(c)

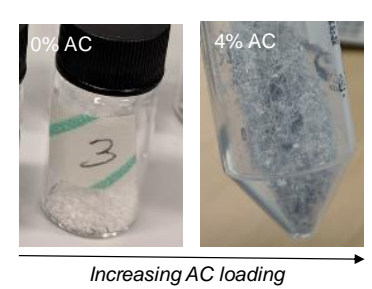

(b)

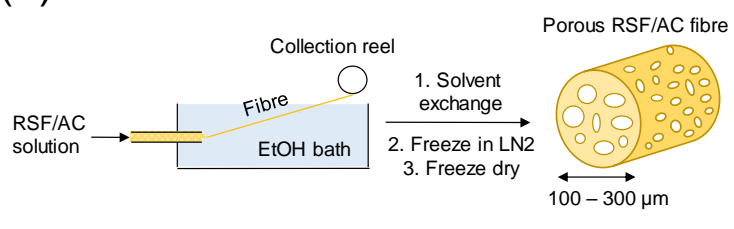

(d)
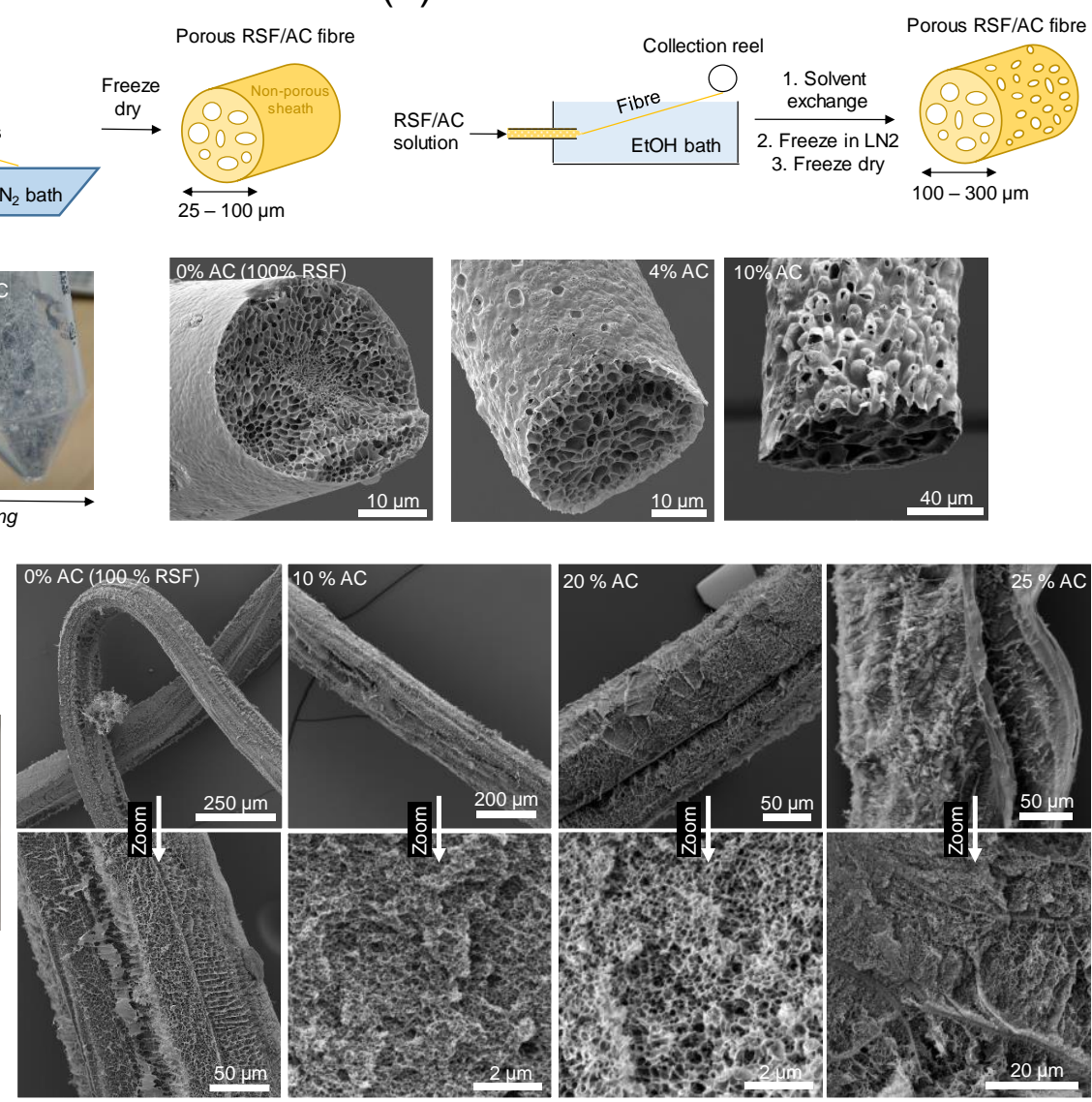

Figure 1. Schematic representation of (a) the cryogenic solution blow spinning (Cryo-SBS) and (b) the cryogenic wet-spinning (Cryo-WS) fibre spinning rigs. (c) Visible light and SEM images of RSF fibres produced by Cryo-SBS with increasing AC loading (left to right, 0, 4 and $10 \mathrm{wt}$ \% \%). (d) Visible light and SEM images of RSF fibres produced by Cryo-WS with increasing AC loading (left to right, 0, 10, 20 and 25 wt. \%). 
Table 1. Summary of the physical properties of the porous regenerated silk fibroin (RSF) and RSF/activated carbon (AC) fibres produced. Approximate fibre and macropore diameters (Ø) determined through multiple measurements from SEM images ( \pm standard deviation).

\begin{tabular}{|c|c|c|c|c|c|c|c|}
\hline Method & $\begin{array}{c}\text { AC } \\
\text { Loading } \\
\text { [wt. \%] }\end{array}$ & $\begin{array}{c}\text { Average } \\
\text { Fibre } \varnothing \\
{[\mu \mathrm{m}]}\end{array}$ & $\begin{array}{c}\text { Average } \\
\text { Macropore } \varnothing \\
{[\mu \mathrm{m}]}\end{array}$ & $\begin{array}{c}\mathrm{N}_{2} \text { BET } \\
\text { SSA } \\
{\left[\mathrm{m}^{2} \cdot \mathrm{g}^{-1}\right]}\end{array}$ & $\begin{array}{c}\text { Accessible } \\
\text { SSA } \\
{[\%]}\end{array}$ & $\begin{array}{c}\text { Micropore } \\
\text { Vol. } \\
{\left[\mathrm{cm}^{3} \cdot \mathrm{g}^{-1}\right]}\end{array}$ & $\begin{array}{c}\text { Max. Cyclohexane } \\
\text { Uptake } \\
{[w / w \%]}\end{array}$ \\
\hline (AC only) & 100 & $\mathrm{n} / \mathrm{a}$ & $\mathrm{n} / \mathrm{a}$ & 697 & 100 & 0.358 & 22.8 \\
\hline Cryo-SBS & 0 & $43 \pm 9$ & $1.1 \pm 0.4$ & 34 & 100 & 0.038 & $\mathrm{n} / \mathrm{a}$ \\
\hline Cryo-SBS & 4 & $23 \pm 4$ & $1.8 \pm 0.5$ & 17 & 28 & 0.015 & $\mathrm{n} / \mathrm{a}$ \\
\hline Cryo-SBS & 10 & $55 \pm 6$ & $10.4 \pm 3.1$ & 44 & 44 & 0.051 & $\mathrm{n} / \mathrm{a}$ \\
\hline Cryo-WS & 0 & $160 \pm 25$ & $1.6 \pm 1.0$ & 79 & 100 & 0.032 & 12.9 \\
\hline Cryo-WS & 10 & $124 \pm 14$ & $0.1 \pm 0.04$ & 121 & 86 & 0.035 & 26.6 \\
\hline Cryo-WS & 15 & $110 \pm 16$ & $0.68 \pm 0.30$ & 134 & 79 & 0.018 & 27.0 \\
\hline Cryo-WS & 20 & $180 \pm 30$ & $0.14 \pm 0.05$ & 143 & 71 & 0.047 & 25.5 \\
\hline Cryo-WS & 25 & $190 \pm 29$ & $0.54 \pm 0.45$ & 210 & 90 & 0.156 & 22.4 \\
\hline
\end{tabular}

\section{Results}

RSF spinning dopes were prepared following a previously published protocol detailed in the SI $[11,19]$. Porous RSF fibres were prepared via Cryo-SBS (Figure 1a) following a protocol previously developed within our group, $[10,11,20]$ however, the Cryo-WS method (Figure $1 b$ ) has, to the authors' knowledge, not been reported previously. For the Cryo-SBS method, RSF and colloidal RSF-AC mixtures were spun directly into a liquid nitrogen $\left(\mathrm{LN}_{2}\right)$ bath, collected and freeze dried (Figure 1a). This rapid freezing induces the formation of macropores via ISISA [9-14]. The obtained fibres were approximately $0.2-1 \mathrm{~cm}$ in length and $25-60 \mu \mathrm{m}$ in diameter, and darkened uniformly with increasing AC content (Figure 1c). Fibres with an AC content greater than $10 \mathrm{wt} . \%$ could not be produced due to instability of the fibre jet-resulting in droplet formation rather than a continuous stream of fibres. Their relatively short length meant they would be unsuitable for processing into a woven fabric, but could potentially be employed as a non-woven material (i.e., a felt). Scanning electron microscopy (SEM) imaging revealed macropores with average diameters ranging from 1-13 $\mu \mathrm{m}$ in diameter (Figure 1c), which are fairly small for a freeze-casting method-which typically produces pores in the range of $5-50 \mu \mathrm{m}[21,22]$ The relatively small pores are likely due to rapid freezing from the high surface area-to-volume ratio of the fibres and high temperature differential between the fibres and $\mathrm{LN}_{2}$, since the pore sizes from freeze-casting methods are inversely proportional to the velocity of ice crystal growth [22]. It can also be observed from the SEM images that the fibres have a seemingly non-porous outer sheath. This likely arises from evaporation-induced phase separation at the surface of the fibre as it travels through the air gap between the nozzle and the cryogenic bath; a phenomenon also observed for some dry-jet wet spun fibres [23]. For the Cryo-WS method, RSF and colloidal RSF-AC mixtures were wet-spun into an ethanol coagulation bath akin to previous literature reports for wet-spun RSF fibres (Figure 1b) [24-28]. The wet fibres were then subjected to solvent exchange in deionised (DI) water, before being rapidly frozen by submersion in $\mathrm{LN}_{2}$ followed by freeze-drying. The dry fibres were continuous in length and had diameters ranging from 100-220 $\mu \mathrm{m}$ (Figure 1d); smaller diameter fibres could feasibly be produced by employing a smaller diameter extrusion nozzle or by employing post-spin drawing. The fibres were fairly flexible to handle and also darkened with increasing AC content. AC loadings in excess of $25 \mathrm{wt} . \%$ could not be achieved since these fibres' mechanical properties after spinning were too poor and could not be collected without breaking apart. The fibres had average macropore diameters ranging from $0.1-1 \mu \mathrm{m}$, which-to the author's knowledge-are among the smallest reported for an ice-templating based method (where water is the solvent). This is likely due to the rapid freezing resulting in relatively small ice crystals and hence small pores after freeze-dying [22]. Xia and co-workers produced porous fibres with similarly small $(\sim 0.1 \mu \mathrm{m})$ macropores via a cryogenic electrospinning technique (employing organic solvents rather than water), suggesting a similar underlying pore formation mechanism [13]. 
The SSA and micropore volume of the fibres were determined through $\mathrm{N}_{2}$ gas sorption and Brunauer-Emmett-Teller (BET) analysis (Figure 2 and Table 1). The surface area of the Cryo-SBS fibres with $0 \%$ AC was $34 \mathrm{~m}^{2} \cdot \mathrm{g}^{-1}$, which is fairly high for ISISA-derived pores which typically have SSAs less than $15 \mathrm{~m}^{2} \cdot \mathrm{g}^{-1}$ [21,22]. This relatively high surface area is likely a result of the relatively small macropores as observed by SEM. A 4\% AC loading saw a decrease in SSA to $17 \mathrm{~m}^{2} \cdot \mathrm{g}^{-1}$, only $28 \%$ of the theoretical SSA considering the masses of the silk (at $34 \mathrm{~m}^{2} \cdot \mathrm{g}^{-1}$ ) and AC (at $697 \mathrm{~m}^{2} \cdot \mathrm{g}^{-1}$ ) individually, suggesting that most pores were inaccessible. A $10 \%$ AC loading yielded an SSA of $44 \mathrm{~m}^{2} \cdot \mathrm{g}^{-1}$, which was $44 \%$ of the theoretical SSA $\left(100 \mathrm{~m}^{2} \cdot \mathrm{g}^{-1}\right)$. This relatively poor performance could be attributed to the outer non-porous sheath restricting gaseous diffusion to the $\mathrm{AC}$, or rapid freezing resulting in smothering of the AC particles within the RSF polymer. Analysis of the isotherms revealed an increase in micropore volume from 0.038 to $0.05 \mathrm{~cm}^{3} \cdot \mathrm{g}^{-1}$ with a $10 \%$ AC loading, suggesting the increase in SSA was largely from the microporous AC. The Cryo-WS fibres with $0 \%$ AC had a significantly higher SSA at $79 \mathrm{~m}^{2} \cdot \mathrm{g}^{-1}$ which — to the best of our knowledge-is the highest reported SSA for an ice-templated polymeric material. Incorporation of AC gradually increased the SSA to a maximum value of $210 \mathrm{~m}^{2} \cdot \mathrm{g}^{-1}$ with a $25 \%$ AC loading-corresponding to an accessible surface area of $90 \%$ (Figure 2c). Use of ACs with higher SSAs (the employed AC had a SSA of $697 \mathrm{~m}^{2} \cdot \mathrm{g}^{-1}$, but some ACs can exceed $4000 \mathrm{~m}^{2} \cdot \mathrm{g}^{-1}$ ) [29] or other highly microporous materials such as MOFs would likely result in fibres with significantly higher SSAs.

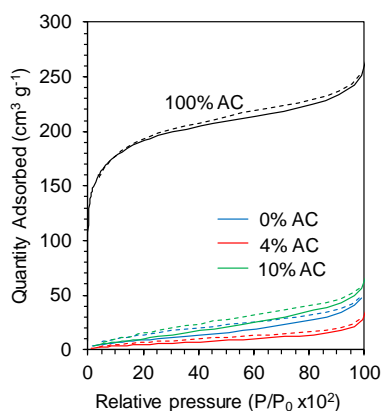

(a)

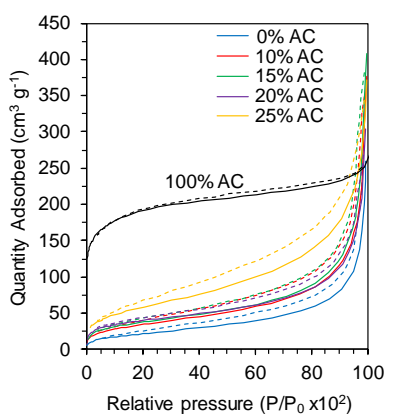

(b)

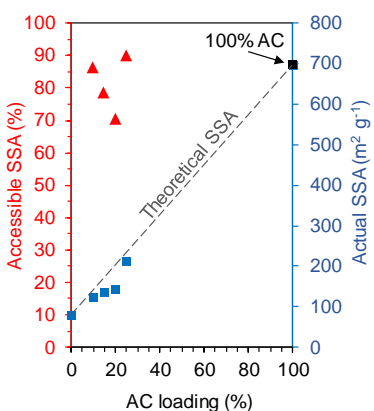

(c)

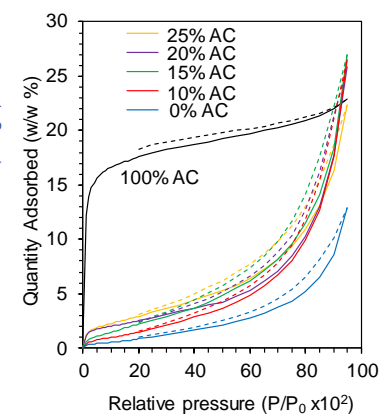

(d)

Figure 2. $\mathrm{N}_{2}$ gas sorption isotherms for porous RSF fibres produced by (a) Cryo-SBS with 0,4 and 10 wt.\% AC loading and (b) Cryo-WS with 0, 10, 15, 20 and 25 wt. \% AC loading. Dashed lines indicate desorption, $100 \%$ AC included for comparison. (c) Relationship between AC loading and both $\%$ accessible SSA and actual SSA for RSF fibres produced by Cryo-WS. (d) Cyclohexane adsorption isotherms for RSF fibres produced through Cryo-WS with 0-25 wt. \% AC loading. 100\% AC included for comparison.

The efficacy of the fibres for adsorption of VOCs was assessed through Dynamic Vapour Sorption (DVS); here, cyclohexane was employed as a representative VOC for proof of principle. Porous fibres produced via Cryo-WS displayed significant adsorption capacity for VOCs (Table 1, Figure 2d.), with the majority of adsorption occurring at relatively high partial pressures-suggesting macropores from ISISA were largely contributing to adsorption rather than micropores from the AC. This was corroborated by the fact that an increase in AC loading from $10 \%$ to $25 \%$ had little effect on cyclohexane adsorption, although $0 \%$ AC loading had a smaller adsorption capacity. No significant cyclohexane adsorption could be detected for the Cryo-SBS fibres however, possibly due their lower SSAs or the presence of the non-porous sheath outer restricting diffusion to the porous core.

The mechanical properties for the fibres were investigated through uniaxial tensile testing (Figure S1), however the highly porous nature of the fibres meant the true cross-sectional surface area of the fibres (needed to convert force to stress) could not be accurately determined, and therefore calculation of the tensile strength was not possible. Contact angle measurements on RSF fibre mats produced by Cryo-SBS with $0 \%$ and $4 \%$ AC loading revealed increased hydrophobicity with an increasing AC content (Figure S2.). This is likely due to the relatively hydrophobic nature of AC 
on the surface of the fibres reducing their wettability, but may also be a result of enhanced surface roughness causing a "lotus-leaf" type repellence effect (Figure S2c)—a more in depth study is needed to confirm this possibility however. Contact angle data could not be obtained for Cryo-WS fibres since their relatively bulky nature meant adequately uniform mats could not be produced. Visible light and cross-polarised microscopy was also performed on the fibres to visualise the distribution of AC, a technique which was recently employed to visualise the distribution of graphene within hollow aramid fibres (Figure S3) [30]. This revealed a fairly uniform distribution of AC within the fibres (i.e., no significant agglomeration observed).

The composition and microstructure of the dry fibres were analysed through wide angle X-ray diffraction (WAXD) and Fourier-transform infrared spectroscopy (FTIR). Natural silk has a polycrystalline structure arising from ordered $\beta$-sheet domains, which has also been observed in some RSF-derived materials [24-26]. The obtained WAXD patterns were, however, indistinguishable from a background measurement, suggesting low crystallinity within these porous fibres (Figure S4). The high void volume in the porous fibres could also account for the low WAXD signal strength. FTIR was employed to probe the protein secondary structure of the RSF fibres through analysis of the amide I region of the spectrum (1600-1700 $\left.\mathrm{cm}^{-1}\right)$, allowing determination of the relative percentage of secondary structural features (i.e., random coils, $\alpha$-helixes, $\beta$-sheets and $\beta$-turns). This revealed a high content of amorphous features relative to crystalline $\beta$-sheets, in concordance with the WAXD data. Post-treatment of the RSF fibres with ethanol, which has been shown to induce $\beta$-sheet formation, [11] was also performed-resulting in a significant increase (approx. 1.7-fold) in $\beta$-sheet features for the porous RSF fibres from both fibre spinning techniques. Post-treatment with ethanol could therefore be exploited to moderate the mechanical properties of the fibres, since a higher $\beta$-sheet content typically results in stronger, stiffer fibres [31].

\section{Conclusions}

In this work, hierarchically porous RSF fibres loaded with AC were produced through two cryogenic fibre spinning techniques-namely Cryo-SBS and a novel Cryo-WS method. Both of these techniques produced fibres with significantly different properties; notably Cryo-SBS fibres had a porous core and non-porous outer sheath which likely restricted gaseous diffusion, compromising accessible SSA and hence VOC adsorption capacity, these fibres were also discontinuous in length. Cryo-WS fibres, on the other hand, were continuous in length and porous throughout, with exceptionally small macropores for an ice-templating method (c.a., $0.1 \mu \mathrm{m}$ ) with significant VOC adsorption capacity. Further refinement of the spinning techniques may produce mesoporous $(0.05 \mu \mathrm{m})$ fibres with further improved VOC adsorption, and the use of ultra-high surface area ACs or other microporous materials may also offer improvements. With further development, fibres such as these could be incorporated into woven or non-woven materials where their hierarchically porous structure in tandem with high VOC adsorption capacity could provide passive protection against CWAs or other airborne toxins. Drawbacks of such fibres include relatively poor mechanical properties, difficulty of dying/colouration and higher costs than materials typically employed in military uniforms (e.g., 50:50 cotton and polyester blends); but these issues could potentially be mitigated by bonding/knitting the porous fabrics as backing or lining layers to existing established materials. Porous RSF fibres such as these, loaded with other functional substances rather than AC, could have applications in a range of fields, particularly tissue regeneration and controlled drug delivery [32-35]. Finally, the use of genetically engineered silks such as recombinant spider silk could tune the mechanical and textural properties of the silk, or introduce chemical functionality such as additional lysine groups $\left(-\mathrm{NH}_{2}\right)$ to neutralise toxic VOCs or other substances [36].

Supplementary Materials: The following are available online.

Author Contributions: Conceptualization, A.D.R. and J.J.B.; methodology, A.D.R.; characterization and analysis, A.D.R., J.-S.M.L., A.M., M.W.S.; writing—original draft preparation, A.D.R.; reviewing and editing, all authors; 
supervision and project administration, J.J.B., M.D., N.S.S. All authors have read and agreed to the published version of the manuscript.

Funding: This work was funded by DSTL project no. CDE100640 and DSTLX1000101893, with support from the EPSRC/BBSRC Future Biomanufacturing Research Hub (EP/S01778X/1). We also acknowledge the SYNBIOCHEM center (grant No. BB/M017702/1) and Henry Royce Institute for Advanced Materials (EP/R00661X/1, EP/S019367/1, $\mathrm{EP} / \mathrm{P} 025021 / 1$ and EP/P025498/1) for support and equipment use.

Acknowledgments: We kindly acknowledge Stuart Morse for assistance with mechanical testing and The University of Manchester X-ray Diffraction Laboratory (Department of Materials) for assistance with WAXD. We also thank Sylvain Deville for helpful comments during the open peer review period.

Conflicts of Interest: The authors declare no conflict of interest.

\section{References}

1. Johnson, B.J.; Melde, B.J.; Moore, M.H.; Taft, J.R. Deposition of porous sorbents on fabric supports. J. Vis. Exp. 2018, 57331. [CrossRef]

2. Levine, L.; Johnson, R.F.; Teal, W.B., Jr.; Cadarette, B.S.; Merullo, D.J. Joint Service Lightweight Integrated Suit Technology Program: Heat Strain Evaluation in an Environmental Chamber and in the Field; [Technical Report]; Army Research Inst Of Environmental Medicine: Natick MA, USA, 1998; pp. 1-112.

3. Roberts, A.D.; Li, X.; Zhang, H. Porous carbon spheres and monoliths: Morphology control, pore size tuning and their applications as Li-ion battery anode materials. Chem. Soc. Rev. 2014, 43, 4341-4356. [CrossRef] [PubMed]

4. Ensikat, H.J.; Ditsche-Kuru, P.; Neinhuis, C.; Barthlott, W. Superhydrophobicity in perfection: The outstanding properties of the lotus leaf. Beilstein J. Nanotechnol. 2011, 2, 152-161. [CrossRef] [PubMed]

5. López-Maya, E.; Montoro, C.; Rodríguez-Albelo, L.M.; Aznar Cervantes, S.D.; Lozano-Pérez, A.A.; Cenís, J.L.; Barea, E.; Navarro, J.A.R. Textile/Metal-Organic-Framework Composites as Self-Detoxifying Filters for Chemical-Warfare Agents. Angew. Chemie Int. Ed. 2015, 54, 6790-6794. [CrossRef] [PubMed]

6. Zhao, J.; Losego, M.D.; Lemaire, P.C.; Williams, P.S.; Gong, B.; Atanasov, S.E.; Blevins, T.M.; Oldham, C.J.; Walls, H.J.; Shepherd, S.D.; et al. Highly Adsorptive, MOF-Functionalized Nonwoven Fiber Mats for Hazardous Gas Capture Enabled by Atomic Layer Deposition. Adv. Mater. Interfaces 2014, 1, 1400040. [CrossRef]

7. Liu, Y.; Howarth, A.J.; Vermeulen, N.A.; Moon, S.-Y.; Hupp, J.T.; Farha, O.K. Catalytic degradation of chemical warfare agents and their simulants by metal-organic frameworks. Coord. Chem. Rev. 2017, 346, 101-111. [CrossRef]

8. Columbus, I.; Waysbort, D.; Shmueli, L.; Nir, I.; Kaplan, D. Decomposition of Adsorbed VX on Activated Carbons Studied by 31P MAS NMR. Environ. Sci. Technol. 2006, 40, 3952-3958. [CrossRef]

9. Gutiérrez, M.C.; Ferrer, M.L.; del Monte, F. Ice-Templated Materials: Sophisticated Structures Exhibiting Enhanced Functionalities Obtained after Unidirectional Freezing and Ice-Segregation-Induced Self-Assembly. Chem. Mater. 2008, 20, 634-648. [CrossRef]

10. Medeiros, E.L.G.; Braz, A.L.; Porto, I.J.; Menner, A.; Bismarck, A.; Boccaccini, A.R.; Lepry, W.C.; Nazhat, S.N.; Medeiros, E.S.; Blaker, J.J. Porous Bioactive Nanofibers via Cryogenic Solution Blow Spinning and Their Formation into 3D Macroporous Scaffolds. ACS Biomater. Sci. Eng. 2016, 2, 1442-1449. [CrossRef]

11. Magaz, A.; Roberts, A.D.; Faraji, S.; Nascimento, T.R.L.; Medeiros, E.S.; Zhang, W.; Greenhalgh, R.D.; Mautner, A.; Li, X.; Blaker, J.J. Porous, Aligned, and Biomimetic Fibers of Regenerated Silk Fibroin Produced by Solution Blow Spinning. Biomacromolecules 2018, 19, 4542-4553. [CrossRef]

12. Scotti, K.L.; Dunand, D.C. Freeze casting-A review of processing, microstructure and properties via the open data repository, FreezeCasting.net. Prog. Mater. Sci. 2018, 94, 243-305. [CrossRef]

13. McCann, J.T.; Marquez, M.; Xia, Y. Highly Porous Fibers by Electrospinning into a Cryogenic Liquid. J. Am. Chem. Soc. 2006, 128, 1436-1437. [CrossRef] [PubMed]

14. Zhang, H.; Hussain, I.; Brust, M.; Butler, M.F.; Rannard, S.P.; Cooper, A.I. Aligned two-and three-dimensional structures by directional freezing of polymers and nanoparticles. Nat. Mater. 2005, 4, 787. [CrossRef] [PubMed]

15. Deville, S. Ice-templating, freeze casting: Beyond materials processing. J. Mater. Res. 2013, 28, $2202-2219$. [CrossRef]

16. Zhang, H.; Cooper, A.I. Aligned Porous Structures by Directional Freezing. Adv. Mater. 2007, 19, $1529-1533$. [CrossRef] 
17. Qian, L.; Zhang, H. Controlled freezing and freeze drying: A versatile route for porous and micro-/nano-structured materials. J. Chem. Technol. Biotechnol. 2011, 86, 172-184. [CrossRef]

18. Li, M.; Wu, Z.; Zhang, C.; Lu, S.; Yan, H.; Huang, D.; Ye, H. Study on porous silk fibroin materials. II. Preparation and characteristics of spongy porous silk fibroin materials. J. Appl. Polym. Sci. 2001, 79, 2192-2199. [CrossRef]

19. Rockwood, D.N.; Preda, R.C.; Yücel, T.; Wang, X.; Lovett, M.L.; Kaplan, D.L. Materials fabrication from Bombyx mori silk fibroin. Nat. Protoc. 2011, 6, 1612-1631. [CrossRef]

20. Greenhalgh, R.D.; Ambler, W.S.; Quinn, S.J.; Medeiros, E.S.; Anderson, M.; Gore, B.; Menner, A.; Bismarck, A.; Li, X.; Tirelli, N.; et al. Hybrid sol-gel inorganic/gelatin porous fibres via solution blow spinning. J. Mater. Sci. 2017, 52, 9066-9081. [CrossRef]

21. Deville, S. The lure of ice-templating: Recent trends and opportunities for porous materials. Scr. Mater. 2018, 147, 119-124. [CrossRef]

22. Deville, S. Freezing Colloids: Observations, Principles, Control, and Use: Applications in Materials Science, Life Science, Earth Science, Food Science, and Engineering; Springer: Berlin, Germany, 2017.

23. Chatzi, E.G.; Koenig, J.L. Morphology and Structure of Kevlar Fibers: A Review. Polym. Plast. Technol. Eng. 1987, 26, 229-270. [CrossRef]

24. Zhang, F.; Lu, Q.; Yue, X.; Zuo, B.; Qin, M.; Li, F.; Kaplan, D.L.; Zhang, X. Regeneration of high-quality silk fibroin fiber by wet spinning from $\mathrm{CaCl}$-formic acid solvent. Acta Biomater. 2015, 12, 139-145. [CrossRef] [PubMed]

25. Marsano, E.; Corsini, P.; Arosio, C.; Boschi, A.; Mormino, M.; Freddi, G. Wet spinning of Bombyx mori silk fibroin dissolved in $\mathrm{N}$-methyl morpholine $\mathrm{N}$-oxide and properties of regenerated fibres. Int. J. Biol. Macromol. 2005, 37, 179-188. [CrossRef] [PubMed]

26. Zuo, B.; Liu, L.; Wu, Z. Effect on properties of regenerated silk fibroin fiber coagulated with aqueous methanol/ethanol. J. Appl. Polym. Sci. 2007, 106, 53-59. [CrossRef]

27. Yan, J.; Zhou, G.; Knight, D.P.; Shao, Z.; Chen, X. Wet-Spinning of Regenerated Silk Fiber from Aqueous Silk Fibroin Solution: Discussion of Spinning Parameters. Biomacromolecules 2010, 11, 1-5. [CrossRef] [PubMed]

28. Um, I.C.; Kweon, H.; Lee, K.G.; Ihm, D.W.; Lee, J.-H.; Park, Y.H. Wet spinning of silk polymer: I. Effect of coagulation conditions on the morphological feature of filament. Int. J. Biol. Macromol. 2004, 34, 89-105. [CrossRef]

29. Lee, J.-S.M.; Briggs, M.E.; Hasell, T.; Cooper, A.I. Hyperporous Carbons from Hypercrosslinked Polymers. Adv. Mater. 2016, 28, 9804-9810. [CrossRef]

30. Roberts, A.D.; Kelly, P.; Bain, J.; Morrison, J.J.; Wimpenny, I.; Barrow, M.; Woodward, R.T.; Gresil, M.; Blanford, C.; Hay, S.; et al. Graphene-aramid nanocomposite fibres via superacid co-processing. Chem. Commun. 2019, 55, 11703-11706. [CrossRef]

31. Wei, W.; Zhang, Y.; Zhao, Y.; Shao, H.; Hu, X. Studies on the post-treatment of the dry-spun fibers from regenerated silk fibroin solution: Post-treatment agent and method. Mater. Des. 2012, 36, 816-822. [CrossRef]

32. Guan, G.; Bai, L.; Zuo, B.; Li, M.; Wu, Z.; Li, Y.; Wang, L. Promoted dermis healing from full-thickness skin defect by porous silk fibroin scaffolds (PSFSs). Biomed. Mater. Eng. 2010, 20, 295-308. [CrossRef]

33. Guan, G.; Bai, L.; Zuo, B.; Li, M.; Wu, Z.; Wang, L.; Li, Y. Distinct tissue responses to porous silk fibroin scaffolds (PSFSs) and polyvinyl alcohol (PVA) sponges in vivo. In Proceedings of the 2010 3rd International Conference on Biomedical Engineering and Informatics, Yantai, China, 16-18 October 2010; IEEE: Piscataway, NJ, USA, 2010; Volume 4, pp. 1668-1672.

34. Guan, G.; Wang, L.; Li, M.; Bai, L. In vivo biodegradation of porous silk fibroin films implanted beneath the skin and muscle of the rat. Biomed. Mater. Eng. 2014, 24, 789-797. [CrossRef] [PubMed]

35. Roberts, A.D.; Zhang, H. Poorly water-soluble drug nanoparticles via solvent evaporation in water-soluble porous polymers. Int. J. Pharm. 2013, 447, 241-250. [CrossRef] [PubMed]

36. Roberts, A.D.; Finnigan, W.; Wolde-Michael, E.; Kelly, P.; Blaker, J.J.; Hay, S.; Breitling, R.; Takano, E.; Scrutton, N.S. Synthetic biology for fibers, adhesives, and active camouflage materials in protection and aerospace. MRS Commun. 2019, 1-19. [CrossRef] [PubMed]

Sample Availability: Samples of the compounds listed in Table 1 are available from the authors.

(C) 2020 by the authors. Licensee MDPI, Basel, Switzerland. This article is an open access article distributed under the terms and conditions of the Creative Commons Attribution (CC BY) license (http://creativecommons.org/licenses/by/4.0/). 